\title{
Costs of Custom Power Devices Versus the Financial Losses of Voltage Sags and Short Interruptions: A Techno-economic Analysis
}

\author{
Mahmoud A. El-Gammal, Amr Y. Abou-Ghazala and Tarek I. El-Shennawy
}

\begin{abstract}
The increased concern about the financial losses due to voltage sags and interruptions plus the advancements in power electronics technology have led to the innovation of very fast acting intervening equipment that can mitigate such disturbances at the facility entrance. Although significant improvements in the overall power quality can be achieved, however, the high cost of these custom power devices can offset the benefits resulting from their application. The problem therefore, is one of finding a compromised solution that makes technical and financial sense. In this paper, the technical merits of the custom power devices are highlighted, along with their effectiveness in mitigating voltage sags and/or short interruptions. The costs of each application are financially analyzed together with a procedure for the decision maker to compare the payback or the revenue of investment in such devices. A case study of an oil refinery in Alexandria, Egypt is considered to illustrate the proposed procedure.
\end{abstract}

Index Terms - Custom Power Devices, Power Quality, Techno-economic Analysis, Voltage Sags.

\section{INTRODUCTION}

Voltage sags and short interruptions can be generally described as brief voltage reduction events, followed by restoration of the normal supply conditions. Voltage sags and short interruptions are probably the most serious power quality problems, as they are frequent causes of tripping electrical equipment in industrial installations, leading to costly process shutdowns [1].

Custom power devices are a special category of power conditioning equipment, used to protect the entire facility from such voltage disturbances. Custom power devices have to work within parts of a cycle, thanks to the advancements in power electronics technology, such that the load bus will not be affected by the supply disturbance [2].

The study work in this paper tries to answer two questions; which custom power device to use and at what cost. The paper proposes a methodology for the decision makers, to

Manuscript received February 3, 2010.

M. A. El-Gammal is the head of the Electrical Power Engineering Department, Faculty of Engineering, Alexandria University, Alexandria 21544 Egypt (e-mail: gammalmah50@yahoo.com).

A. Y. Abou-Ghazala, is the Electrical Power Engineering Department, Faculty of Engineering, Alexandria University, Alexandria 21544 Egypt (e-mail: a.ghazala@electroopower.com).

T. I. El-Shennawy is with Alexandria National Refining and Petrochemicals Co. (ANRPC), Alexandria 23111 Egypt (corresponding author, e-mail : tshennawy@yahoo.com, mob.: (+2012) 3926297, Fax.: (+203) 4446785, Phone(+203) 4264161). compare the technical merits and limitations of these devices, along with an economical evaluation of their costs against the financial losses associated with sags and interruptions.

\section{Voltage SAGS AND SHORT INTERRUPTIONS}

\section{A. Definitions}

The IEEE Std. 1159-2009 defines voltage sag as: A decrease to between 0.1 and $0.9 \mathrm{pu}$ in rms voltage or current at the power frequency for durations of 0.5 cycle to $1 \mathrm{~min}$. The amplitude of voltage sag is the value of the remaining voltage during the sag [3].

The IEEE defines a momentary interruption as: A complete loss of voltage $(<0.1 \mathrm{pu})$ on one or more phase conductors for a time period between 0.5 cycles and $3 \mathrm{~s}$. A temporary interruption is: The complete loss of voltage $(<0.1$ $\mathrm{pu})$ on one or more phase conductors for a time period between $3 \mathrm{~s}$ and $1 \mathrm{~min}$ [3].

The IEC terminology for voltage sag is dip. The IEC defines voltage dip as: A sudden reduction of the voltage at a point in the electrical system, followed by voltage recovery after a short period of time, from half a cycle to a few seconds. The amplitude of a voltage dip is defined as the difference between the voltage during the voltage dip and the nominal voltage of the system expressed as a percentage of the nominal voltage [4].

The IEC defines a short supply interruption as: The disappearance of the supply voltage for a period of time not exceeding $1 \mathrm{~min}$. Short supply interruptions can be considered as voltage dips with 100\% amplitude [4].

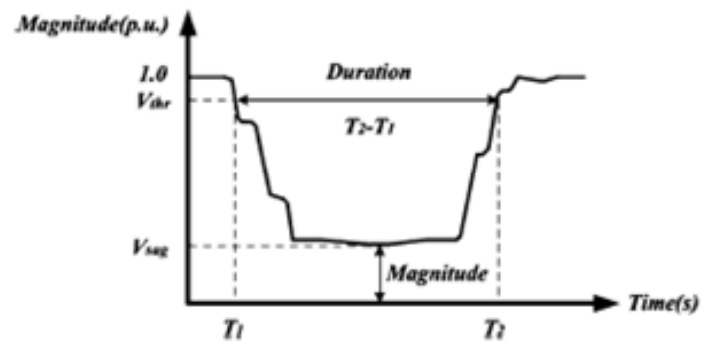

Figure1. Voltage Sag

Fig. 1 shows an rms representation of voltage sag, the sag starts when the voltage decreases to lower than the threshold voltage Vthr ( $0.9 \mathrm{pu})$ at time $\mathrm{T} 1$. The sag continues till T2 at which the voltage recovers to a value over the threshold value, hence the duration of the voltage sag is (T2-T1) and the magnitude of the voltage sag is sag to Vsag [5]. 


\section{B. Causes and Effects}

Consider the transmission and distribution system shown in Fig. 2. When a fault occurs at the distribution feeder (4), the feeder breaker will operate (open), leading to a complete interruption on this feeder. The users on the faulted circuit on the load side of the operating protective device will see a permanent or temporary interruption according to the type of fault and the protective scheme. During fault, the transmission circuit as well as the other feeders will contribute to feed the fault. As a result, all loads on the other three circuits will suffer a temporary voltage sag, which lasts as long as the circuit breaker on the parallel feeder opens and interrupts the flow of the fault current.

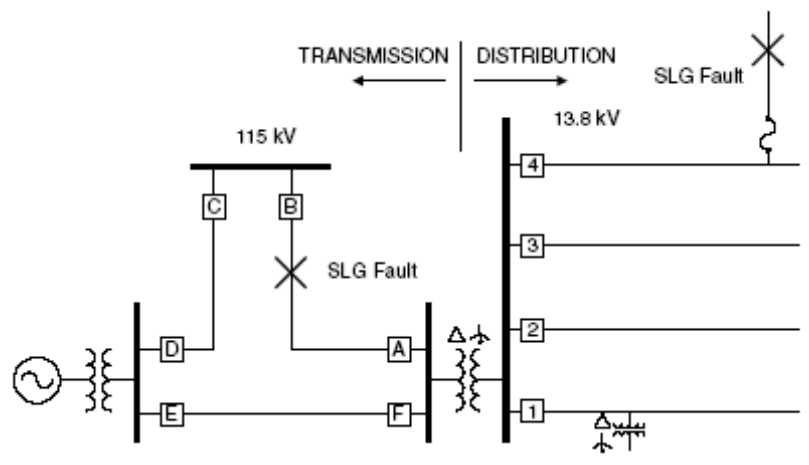

Figure 2. Fault locations on the utility power system

A much more common event would be a fault somewhere on the transmission system. Note that to clear the fault shown on the transmission system of Fig. 2, both breakers on the two sides of the fault must operate. In such case, only one of the two lines supplying the distribution substation has a fault. Therefore, customers supplied from the substation should expect to see only a sag and not an interruption [6].

Reports of voltage sags relate voltage sags to lightning, animal contact, fallen tree limbs, storms and accidents, in addition to unavoidable faults and switching operations on the transmission and distribution networks. Energizing of heavy loads, starting of large motors and transformer saturation can also cause voltage sags, although of shallower values [7-8].

Voltage sags and short interruptions affect the operation of equipment in various forms. Digital electronic devices, particularly those with a memory, are extremely sensitive to very short-duration power disturbances. Programmable logic controllers, adjustable speed drives, and data terminals are a few examples of sensitive loads that often fall victim to momentary voltage disturbances [9].

Industrial loads consisting of large induction motors suffer from sags and short interruptions in a different manner. As the supply voltage to the induction motor decreases, the motor speed decreases. Depending on the severity and the duration of the voltage reduction event, the motor speed may recover to its normal value as the voltage amplitude recovers. If the voltage magnitude and/or duration is lower than certain limits, the motor may stall and would be taken out of the system [10].

\section{Mitigation}

Mitigation equipment can be grouped into two classes:

i) Load-side (equipment level) solutions, which are subdivided into two categories: the first works by providing voltage sag ride-through capability to critical loads. Examples of these devices include Motor-Generator (MG) sets where energy is stored in flywheels and Uninterruptible Power Supplies (UPS) where energy is stored in batteries. The other category works on the transformer feeding the load. Examples of these devices include the Constant Voltage Transformer (CVT) or the ferro-resonance transformer, which is excited at a high point on its saturation curve, thus providing a constant or fixed secondary output voltage regardless of the primary input voltage, and the Static Voltage Regulator (SVR) or electronic tap-changer which changes the turns ratio as fast as possible to compensate for the input voltage variations. Generally, the ratings of these solutions are such that they are best installed directly at the most sensitive loads within the end-user facility, usually at the low voltage level [11].

ii) Source side (facility level) solutions (Custom power devices), applied in the medium voltage distribution system of an electric utility with the purpose of protecting an entire plant, with load ratings of the range of a few MVA [12].

\section{Custom Power DeVICES}

The concept of custom power is the employment of power electronic or static controllers in medium voltage distribution systems for the purpose of supplying a level of power quality that is needed by customers sensitive to power quality disturbances. Custom power controllers may include static switches, inverters, converters, injection transformers, master control modules, and energy storage modules [13].

Existing mitigation equipment or Custom Power Devices as it were conventionally referred to include the solid state or the Static Transfer Switch (STS), working by transferring the load bus to another healthy feeder in sub-cycles, the Dynamic Voltage Restorer (DVR), working by boosting the voltage at the load bus during voltage sags, utilizing an energy storage unit and a voltage source converter, and the Backup Storage Energy Systems (BSES), working by isolating the supply once a disturbance is detected and feeding the load from an energy storage unit and an inverter.

\section{A. Dynamic Voltage Restorer (DVR)}

The DVR sometimes called the Static Series Compensator (SSC), is a custom power device connected in series with the distribution feeder. The DVR provides a controllable voltage, whose phasor adds to the source voltage to obtain the desired load voltage. In its simplest configuration, shown in Fig. 3, the DVR consists of the following components [14]: 


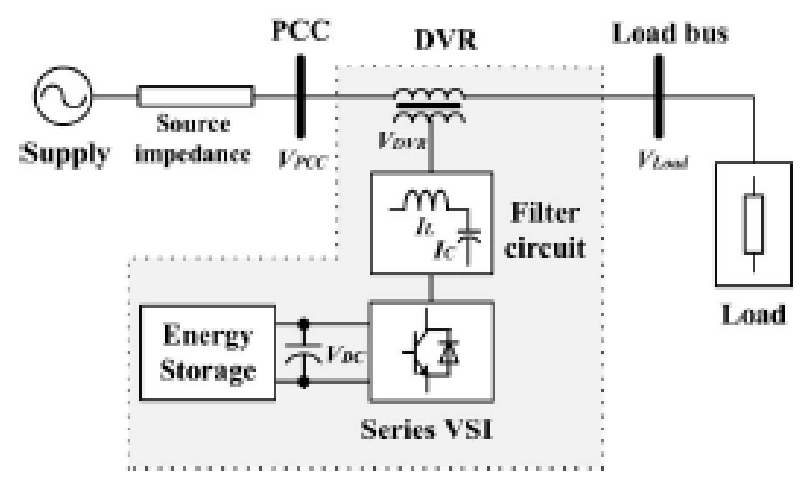

Figure 3. Dynamic Voltage Restorer (DVR)

1. Energy storage unit, which is used to provide the missing energy during the sag condition. Commercially available DVRs use large capacitor banks for energy storage. The capacity of the energy storage device has a big impact on the compensation capability of the system, as it determines the ride-through time for the load. Alternatively, DVRs can be configured to use line energy supply; that is, they absorb the energy that is to be injected into the distribution circuit from the utility feeder itself.

2. Voltage Source Inverter (VSI), or Voltage Source Converter (VSC), which converts the dc voltage from the energy storage unit to a controllable ac voltage to be inserted with the line voltage. Since the vast majority of voltage sags seen on utility systems are unbalanced, mostly due to single-phase events, the VSI must therefore treat each phase independently. Moreover, a sag on one phase may result in a swell on another phase, so the VSI must be capable of handling both sags and swells simultaneously. Therefore, the switches of the inverter are switched independently of each other, normally according to a Pulse Width Modulation (PWM) pattern, with high switching frequency. This ensures fast response and a smooth voltage waveform. The voltage rating of the inverter indicates the maximum injected voltage, which is thus the maximum three-phase sag magnitude that can be compensated for. Existing DVRs are usually sized for $50 \%$ maximum voltage injection.

3. Injecting transformer, with its primary connected in parallel to the output of the VSI and its secondary connected in series between the Point of Common Coupling (PCC) and the Load bus, and which injects the controllable three phase voltage vDVR to the PCC voltage VPCC, so that the load bus voltage VLoad remains almost unaffected by the sag condition.

4. Filter circuit, normally, a second-order LC filter is inserted between the inverter and the transformer to cancel high frequency harmonic components in the inverter output voltage.

5. Bypass switches and Control circuits, through which the DVR may be configured to operate as a standby compensator where the inverter is not actively in the circuit until triggered by a voltage sag event. Alternatively, the DVR may be working continuously during normal and abnormal conditions.

The world's first DVR, built by Westinghouse (now part of Siemens), was installed in 1996 in USA and its rating was
2 MVA [15]. The largest reported DVR was sized $2 * 22.5$ MVA (modular) built by ABB [16].

The first major disadvantage of the DVR is that many loads including large ac motors and transformers will draw a large inrush current upon recovery from a voltage sag, which can be a problem if inrush currents approach the current rating of the compensator. The second is that A DVR does not protect a load against an interruption. The DVR should have controls to detect this condition and avoid improper operation [17].

\section{B. Static Transfer Switch (STS)}

Static Transfer Switch (STS) allows fast transfer of sensitive loads from a primary source affected by a disturbance (sag or interruption) to an available alternative healthy feeder. The STS system consists of three main components, as shown in Fig. 4 [18]:

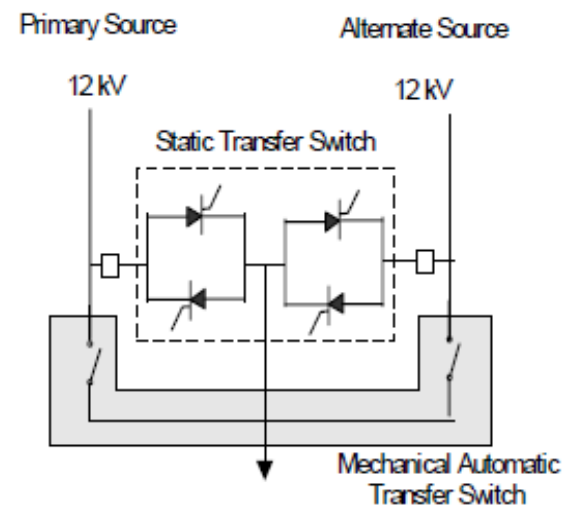

Figure 4. Static Transfer Switch (STS)

1. The static transfer switch STS, consists of two three-phase ac thyristor switches connected back to back (anti-parallel), directing power from two independent feeders to the load.

2. The mechanical bypass switch MTS, operates as a standard mechanical transfer switch when the static transfer switch is out of service.

3. Isolating switches and Control, during normal condition, the switch connected to the primary feeder is kept closed and the switch on the secondary feeder is kept opened. On the detection of a sag or an interruption on the primary feeder, the switches on the secondary feeder turn on immediately and that on the primary feeder turn off at the first natural current zero, hence transferring loads to the healthy feeder, thus providing a seamless transfer of electrical energy between the two feeders.

A requirement is that a secondary feeder, independent from the main source (e.g. a feeder to another substation), must be available. Therefore, this solution is particularly attractive for installations that already have mechanical transfer systems, where upgrading to a static system does not require major changes in the layout of the distribution system. Note that the STS cannot protect against sags originating in the transmission system, which will also affect the alternative supply [18].

The main disadvantage comes from plants with a high percentage of motor loads, a "voltage collapse" problem may occur due to motors drawing much current to re-accelerate, 
which further depresses the voltage in the neighborhood. The result is that, for severe disturbances, the motors may not be able to re-accelerate or may be tripped by protection devices due to the high current drawn. The STS can provide a solution to this problem by transferring the loads to an alternative healthy supply within some milliseconds from the occurrence of the disturbance. However, the time needed for transferring the load is dependent on the type of disturbance and the instant when it occurs, and the transfer time is, in general, higher with an induction motor load, as compared with static load [19].

\section{Backup Storage Energy System (BSES)}

A backup stored energy system (BSES) device disconnects a protected load from the utility supply within milliseconds of the detection of a disturbance and supplies the entire load using stored energy. Typical sources for the stored energy are batteries, flywheels, or superconducting magnetic coils. A BSES unit typically consists of a static source transfer switch (isolation switch), energy storage system, voltage source converter, and isolation transformer, as in Fig. 5.

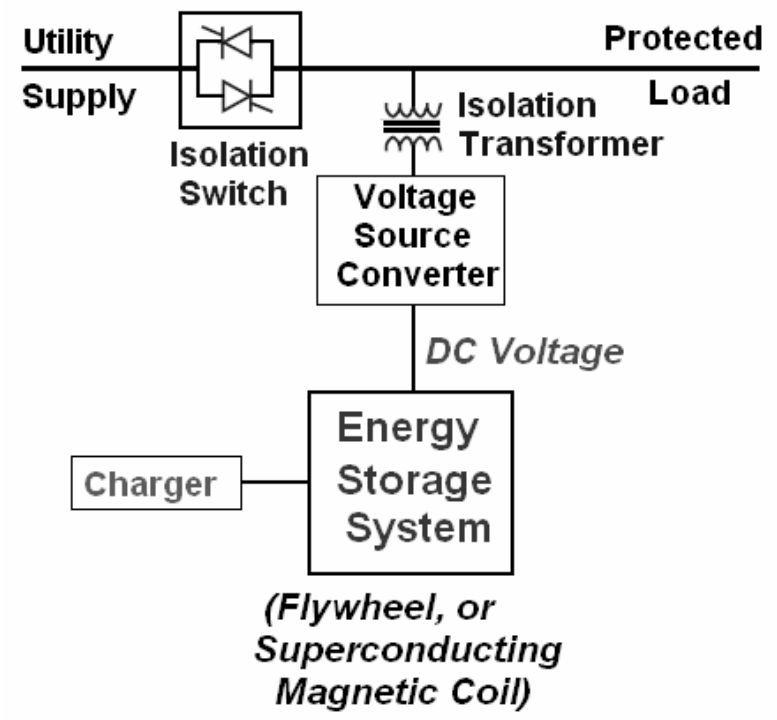

Figure 5. Backup Energy Storage System (BESS)

When a disturbance in the utility supply is detected, an isolation switch will operate to disconnect the protected load from the utility supply in $4 \mathrm{~ms}$ or less. Then the DC stored energy is supplied to the protected load through a voltage source converter that transforms the DC energy to $50 \mathrm{~Hz} \mathrm{AC}$ power. The energy storage device is charged to normal levels by the charger after it discharges [20].

A BSES can be seen as an alternative to an uninterruptible power supply (UPS) when the load power increases. During normal operation, power coming from the ac supply is rectified and then inverted, and the batteries only serve to keep the dc bus voltage constant. During a voltage sag or interruption, the battery block releases energy to supply the load for minutes or even hours, depending on the storage capacity. The UPS is the standard solution for low-power equipment like computers, but for higher-power loads the costs associated with conversion losses and maintenance of the batteries become too high. In a BSES, to avoid high steady-state losses, the sensitive load is normally supplied by the utility feeder and isolated from the power system by a static switch as soon as a disturbance is detected, and supplied by the VSC. One of the main advantages to the BSES compared to the DVR is that it is able to carry a load through a voltage interruption. Because of this, however, its storage requirements are higher. On the other hand, since a BSES unit disconnects the protected load from the utility system, its converter must be rated to carry the entire rating of the protected load. This differs from a DVR, which only injects voltage in addition to the depressed utility voltage and may need only to be sized to carry up to half the rating of the protected load [20].

\section{ECONOMIC EVALUATION}

\section{A. Losses due to sags and interruptions}

A common misconception is that power quality issues are technical problems, but in fact, power quality is a techno-economic problem. Reference [21] estimated the average costs of disturbances as shown in Table I:

TABLE I LOSSES DUE TO SAGS AND INTERRUPTIONS

\begin{tabular}{|l|l|}
\hline Sector & $\begin{array}{l}\text { Cost of voltage sags and interruption / } \\
\text { event (in US \$) }\end{array}$ \\
\hline Semiconductor Industry & $2,500,000$ \\
\hline Credit card processing & 250,000 \\
\hline Equipment manufacturing & 100,000 \\
\hline Automobile industry & 75,000 \\
\hline Chemical industry & 50,000 \\
\hline Paper manufacturing & 30,000 \\
\hline
\end{tabular}

It should be noted that not all voltage sags lead to process shutdown. Costs will typically vary with the severity of the sag. This relationship can often be defined by a matrix of weighting factors, using the cost of a momentary interruption as the base. If a voltage sag to $50 \%$ causes $80 \%$ of the economic impact that an interruption causes, then the weighting factor for a $50 \%$ sag would be 0.8 [22]

Financial losses due to tripping events can be calculated according to [23]:

Losses $=$ Value of lost production + shutdown costs shutdown savings

The value of lost production is equal to the customer's expected revenue without the trip. Shutdown costs include equipment damage costs, material damage costs, backup generation costs, labor costs, and any penalties due to delay in product delivery, shipping, etc. Shutdown savings include costs of labor and materials that were not used during the outage, the value of fuel and electricity that was not used, and the value of any scrap.

The above discussion assumes that all future PQ events and various costs associated with mitigation devices are exactly known. However, none of these data is known with certainty in reality, thus opening the door for probabilistic methods, which treat all inputs as random variables. The output in this case will not be a single answer but a probability distribution of all the possible outcomes for the input values. Stochastic / probabilistic methods were used to estimate the financial losses due to voltage sags and interruptions [24]. 


\section{B. Custom Power Devices Costs}

Each solution technology needs to be characterized in terms of cost and effectiveness. In broad terms, the solution cost should include [25]:

1) Fixed Costs: The fixed costs mainly consist of the mitigation device cost and the cost to install it including labor hours, footprint of the device, time and so forth.

2) Operating Costs: The operating or variable costs are those which allow the mitigation device to work. These operating costs consist of heating losses, maintenance and additional costs such as replacement of batteries at the end of their life, air conditioning to cool the battery room.

The investment costs for the used mitigation methods are given in Table II [22].

TABLE II EXAMPLE COSTS FOR DIFFERENT PQ MITIGATION TECHNIQUES

\begin{tabular}{|l|c|c|}
\hline Alternative & Initial Cost $(\$)$ & $\begin{array}{l}\text { Annual } \\
\text { costs }(\%)\end{array}$ \\
\hline BSES (Battery ride through) & $500 \$ / \mathrm{kVA}$ & $15 \%$ \\
\hline DVR (50\% voltage boost) & $300 \$ / \mathrm{kVA}$ & $5 \%$ \\
\hline STS (10 MVA) & $600,000 \$$ & $5 \%$ \\
\hline
\end{tabular}

Table II provides an example of initial costs and annual operating costs for some general technologies used to improve performance for voltage sags and interruptions. Besides the costs, the solution effectiveness of each alternative must be quantified in terms of the performance improvement that can be achieved. Solution effectiveness, like power quality costs, typically will vary with the severity of the power quality disturbance. This relationship can be defined by a matrix of "\% sags avoided" values. Table III illustrates this concept [22].

TABLE III EFFECTIVENESS OF DIFFERENT PQ MITIGATION TECHNIQUES

\begin{tabular}{|l|c|c|c|c|}
\hline Alternative & Interruption & $\begin{array}{l}<50 \% \\
\text { sag }\end{array}$ & $\begin{array}{l}50 \%- \\
70 \% \mathrm{sag}\end{array}$ & $\begin{array}{l}70 \% \mathrm{sag} \\
90 \%\end{array}$ \\
\hline $\begin{array}{l}\text { BSES (Battery ride } \\
\text { through) }\end{array}$ & 100 & 100 & 100 & 100 \\
\hline $\begin{array}{l}\text { DVR (50\% voltage } \\
\text { boost) }\end{array}$ & 0 & 20 & 90 & 100 \\
\hline STS (10 MVA) & 100 & 80 & 70 & 50 \\
\hline
\end{tabular}

The probabilistic methods were also used to estimate the optimal custom power device from an economic view. A Monte Carlo simulation was used for this purpose and was presented in [26].

\section{Financial Analysis}

Several evaluation methods can be used, according to the company's internal evaluation criteria for investment. The most familiar methods are [27-29]:

\section{i) Payback time (PBT)}

The payback time represents the amount of time that it takes for a project to recover its initial cost. When selecting from mutually exclusive projects, the project with the shortest payback is to be preferred.

The PBT can be calculated from eq. (1):

$$
P B T=\frac{\text { Net investment }}{\text { Net annual return }}
$$

Where net investment is the initial cost (mitigation equipment cost + installation cost) and net annual return is the annual expenses (operation + maintenance) subtracted from the annual benefits.

Although widely used, payback time suffers from two drawbacks. First, PBT does not consider the time-value of money. The second flaw is that payback does not consider the effects of different life-spans of the alternatives, thus penalizing projects that have long potential life-spans.

\section{ii) Net present value (NPV)}

The net present value (NPV) of a project indicates the expected impact of the project on the value of the company. Projects with a positive NPV are expected to increase the value of the company. When selecting from mutually exclusive projects, the project with the largest positive NPV should be chosen.

The NPV can be calculated from eq. (2):

$$
N P V=\sum_{t=0}^{n} \frac{(\text { solution net saving })_{\mathrm{t}}}{(1+\mathrm{r})^{\mathrm{t}}}-C_{0}
$$

Where $r$ is the discount rate, $C_{0}$ is the initial investment, $t$ is the number of years, and $n$ is the lifetime of the investment.

Other costs associated with the financial analysis include project engineering expenses of selecting the equipment, purchasing department expenses, freight and receiving expenses, commissioning expenses, and any spare parts requested. This approach is called total system life cycle cost, and should be taken in consideration during the final analysis [30].

\section{Proposed Methodology}

1. Estimate the number and severity of events the plant is subject to per year.

2. Convert the different sags to a per unit interruption base value, cumulate the summated events in one variable; equivalent number of shutdowns / year.

3. Calculate the average total cost of one shutdown.

4. Multiply the result of step (2) by that of step (3) to calculate the annual cost of shutdowns.

5. Investigate the available custom power devices. Get the cost of installation, operation and maintenance costs, and any available technical and economical data.

6. Instead of investing a small fortune in purchasing the required solution, a bank loan could be more attractive. If the required figure is $\mathrm{C}$, then the annual share for the lifespan of the equipment ( $\mathrm{n}$ years) with a discount rate of $r$ can be calculated from eq. (3):

$$
\text { Yearly share }=\frac{\mathrm{C}(1+\mathrm{r} * \mathrm{n})}{\mathrm{n}}
$$

The annualized costs can be calculated based on a 15-year life and an interest rate of $10 \%$. 
7. Determine the total annual cost for each alternative (yearly share + operations and maintenance costs) and costs associated with the unmitigated events.

8. For solution alternatives, make a comparison with the "No-Mitigation" or "Do-Nothing" case. This is the figure calculated in step (4).

9. The optimum solution will be the device which gives a total annual cost lower than the annual costs associated with the shutdown. Note that if none of the alternatives is lower than the threshold, the "No-Mitigation" will be the most economical action.

10. Discuss and comment on the results.

\section{CASE STUdy}

Alexandria National Refining and Petrochemicals Co. (ANRPC) is a refinery based in Alexandria, Egypt, with an average load of $10 \mathrm{MW}$, of which $80 \%$ are directly connected induction motors at various voltage levels $(11,6.3,0.4 \mathrm{kV})$. As the motor torque is directly proportional to the square of the supply voltage, a decrease ( $\mathrm{sag}$ ) to $70 \%$ of the rated voltage will cause the motor torque to decrease to $49 \%$, which may not be sufficient for driving the load. In addition, applying out of phase voltages whenever the voltage is restored may result in transient currents and torques of excessive values. To avoid the risk of damage of the motors' shafts during such events, strict protection settings are applied, causing induction motors to trip, leading to numerous shutdowns.

\section{RESULTS}

1. A 24 months survey is conducted to investigate the number (frequency) and causes of interruptions and sags. The results of the survey are summarized in Table IV:

TABLE IV SiTE SURVEY RESULTS

\begin{tabular}{|l|l|}
\hline Event & No. of events (2 years) \\
\hline Interruption & 2 \\
\hline $\begin{array}{l}\text { Sag magnitude }<75 \% \text { pu \& Sag } \\
\text { duration }>1.5 \mathrm{~s}\end{array}$ & 4 \\
\hline Other minor sags & 25 \\
\hline Total & 31 \\
\hline
\end{tabular}

2. To calculate the annual no. of equivalent events, the settings of the undervoltage protection relay were adjusted to trip for events below $75 \%$ of the nominal voltage for durations of 1.5 seconds. Sags with magnitude and duration more than these settings cause the protection relay to trip leading to the process shutdown. These sags will be weighted the same as the interruptions. Sags resulting in minor or partial effects are weighted $20 \%$.

Equivalent number of shutdowns / year $=(1 * 2+1 * 4+$ $0.2 * 25) / 2=5.5$

3. The cost of one shutdown is estimated by the company financials to be 50,000 US \$ per event.

4. The annual cost of shutdowns $=5.5 * 50,000=275,000$ US $\$$. This is the value to be compared with the annual costs of solution alternatives.

5. Various custom power devices technical and economical data are summarized in Table V.
TABLE V CUSTOM POWER DEVICES DATA

\begin{tabular}{|l|l|l|l|}
\hline Feature & DVR & STS & BSES \\
\hline Interruption & 0 & $90 \%$ & $100 \%$ \\
\hline Sag voltage $>75 \%$ & $100 \%$ & $70 \%$ & $100 \%$ \\
\hline Sag voltage $<75 \%$ & $75 \%$ & $80 \%$ & $100 \%$ \\
\hline Requirements & - & Another feeder & - \\
\hline Initial cost (US \$) & 750,00 & $\begin{array}{l}600,000 \\
+400,000 \quad \text { for } \\
\text { additional feeder (if } \\
\text { needed) }\end{array}$ & $1,500,000$ \\
\hline Annual costs & 0 & 30,000 & 225,000 \\
\hline
\end{tabular}

Note that the DVR cannot mitigate for interruptions. The STS will transfer the load to another feeder, and the high percentage of its capability depends on the situation of the other feeder at the sag instance. Interruptions and severe sags are likely to occur due to internal faults or faults near the substation. Costs of the alternatives are calculated from Table II.

6. To calculate the annual cost of solution, apply eq. (3) for $\mathrm{n}=15$ and $\mathrm{r}=10 \%$ to get the first row of table VI.

7. For each alternative, add to Table VI a second row for the operation and maintenance costs, and a third row for the cost of unmitigated events.

TABLE VI TOTAL COST FOR DIFFERENT ALTERNATIVES

\begin{tabular}{|c|c|c|c|c|}
\hline & \multirow[t]{2}{*}{ DVR } & \multicolumn{2}{|c|}{ STS } & \multirow[t]{2}{*}{ BSES } \\
\hline & & 2 feeders & 1 feeder & \\
\hline $\begin{array}{c}\text { Annual } \\
\text { solution cost In } \\
\text { US \$ } \\
\end{array}$ & 125,000 & 100,000 & 166,666 & 250,000 \\
\hline Annual costs & 37,500 & \multicolumn{2}{|c|}{30,000} & 225,000 \\
\hline $\begin{array}{c}\text { Annual costs of } \\
\text { unmitigated } \\
\text { events }\end{array}$ & 75,000 & \multicolumn{2}{|c|}{62,500} & 0 \\
\hline Total costs & 237,500 & 192,500 & 259,166 & 475,000 \\
\hline
\end{tabular}

8. Comparing the results of Table VI with that of the annual costs of shutdown, it can be better done using the comparison chart of Fig. 6

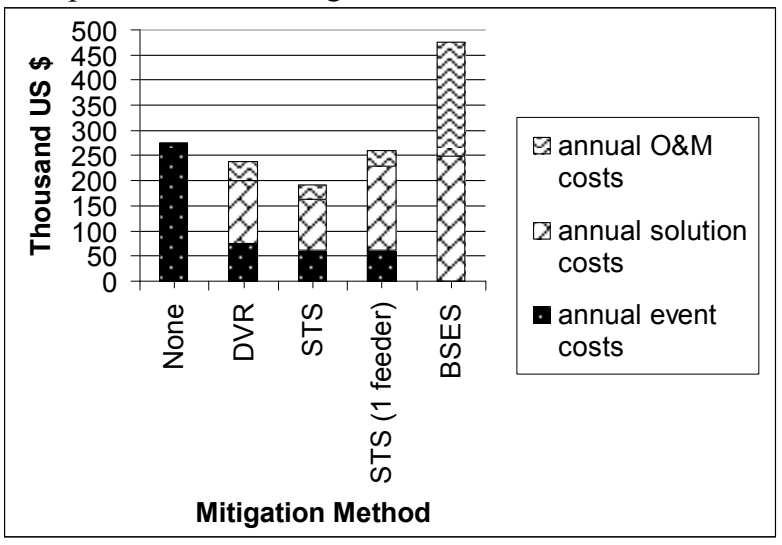

Figure 6. Comparison chart

9. From the comparison results, the following can be concluded:

- The best solution for this particular case study is the implementation of the STS, provided that two feeders already exists.

- If there is only one feeder available, then the best solution in this case is the DVR. 
10. Comments on the results are given in the next section.

11.

\section{COMMENTS AND DISCUSSIONS}

- The results obtained from this specific case study cannot be generalized by any means. Each case should be studied separately according to the proposed procedure.

- The STS and the DVR show justified economical value, however the plant in this case will suffer from a number of voltage sags and interruptions. These solutions are not "cure-all".

- We can have a premium quality of power with no sags or interruptions using the BSES, but this solution is not economic. Its costs are higher than that of the financial losses due to such events. The BSES may be the perfect solution for other applications, where the cost of shutdown may be very expensive.

- There is a certain degree of uncertainty in the figures used throughout the study. Some "hidden costs" may arise. For example, some personnel in the field may interpret a voltage sag affecting only the lighting as a power failure, and start an emergency shutdown. The blinking lights may cause injuries to the personnel, may have the personnel work under tension, may lead to lack of confidence in the electrical department, and many other "soft costs".

- Apart from the estimated financial losses due to the process shutdown (which are based on the expected number of events through the next 10-15 years) and which is assumed to be constant, the costs of the solution alternatives are also susceptible. For example, the cost of the land or the footprint, any training costs for the unqualified personnel who will deal with the new technology, any mis-operation of the equipment, the cost of unmitigated events during the equipment maintenance.

- In the case of requiring another feeder for applying the STS, the estimated figure is based on personal experience and may vary according to the costs of cables, digging and laying, road rites, switchgear modification, and re-engineering the system.

- It could be better to use some probabilistic methods in similar studies, at least as a means to validate the results. This would be addressed in a future work.

- Managers and decision makers often want some indices, payback rates, added values of the investment, etc. In this sight some simple calculations using eq. (1) \& (2) may be helpful yielding the results of Table VII:

TABLE VII ECONOMICAL MEASURES FOR SOLUTION

\begin{tabular}{|c|c|c|c|c|}
\hline & DVR & STS & $\begin{array}{c}\text { STS } \\
\text { requiring } \\
\text { another } \\
\text { feeder }\end{array}$ & BSES \\
\hline $\begin{array}{c}\text { PBT } \\
\text { (years) }\end{array}$ & 4.6 & 3.3 & 5.5 & 30 \\
\hline $\begin{array}{c}\text { NPV (US } \\
\text { \$) }\end{array}$ & 485,975 & 788,095 & 388,095 & $-1,119,700$ \\
\hline
\end{tabular}

It can be easily shown that these results enhance the results of the proposed procedure. The best solution for this case is the STS (provided that two feeders are available) since it results in the minimum Pay Back Time and the maximum positive Net Present Value. If only one feeder is available, the DVR will be the best solution. The BSES needs 30 years to break positive (remember that the lifetime of the equipment is estimated by 15 years only) and its NPV is negative.

\section{CONCLUSION}

The increasing interest in the Power Quality studies in recent years is attributed not only to technical issues, but also to the huge financial losses associated with poor quality of the delivered power. Two of the most relevant problems are voltage sags and short interruptions. These events are caused mainly by system faults and therefore cannot be totally eliminated. Industrial customers seeking for a cost-effective mitigation solution are faced by several custom power devices, all requiring large investments, and probably will not stop all the process shutdowns due to these events.

In this study, a methodology was proposed to help the decision maker to compare the solution alternatives from a techno-economic perspective. The annual cost of voltage sags and interruptions is calculated first, then compared with the annualized solution alternatives costs to select the best solution for each case study.

Future work is still required to address the uncertainty in the estimated values of the parameters used throughout the study.

\section{ACKNOWLEDGMENT}

The authors would like to thank Prof. Dr. Abdel-Mon'em Moussa, Prof. Emeritus at the Faculty of Engineering, Alexandria University, and Vice President of Pharos University in Alexandria, for conducting and supervising the preliminary stages of this study.

\section{REFERENCES}

[1] M. Bollen, Understanding Power Quality Problems: Voltage Sags and Interruptions. $2^{\text {nd }}$ edition, Wiley-IEEE Press, New York, 2000.

[2] A. Ghosh and G. Ledwich, Power Quality Enhancement Using Custom Power Devices. Springer, 2002.

[3] IEEE Std 1159-2009, IEEE Recommended Practice for Monitoring Electric Power Quality.

[4] IEC 61000-2-1, 1990, Electromagnetic Compatibility (EMC) - Part 2: Environment - Section 1: Description of the Environment Electromagnetic Environment for Low-Frequency Conducted Disturbances and Signalling in Public Power Supply Systems.

[5] A. Baggini, Handbook of Power Quality. John Wiley \& Sons, Ltd, London, 2008.

[6] J. Lamoree, D. Muller, P. Vinett, W. Jones, and M. Samotyj, "Voltage Sag Analysis Case Studies", IEEE Trans. on Industry Applications, vol. 30(4), pp. 1083-1089, Jul. 1994.

[7] F. Elmendorf, L. King and M. Ingram, "Correlating Voltage Sags with Line Faults and Lightning", IEEE Computer Applications in Power, pp. 22-24, Apr. 2001.

[8] M. McGranaghan, D. Muller and M. Samotyj, "Voltage Sags in Industrial Systems", IEEE Trans. on Industry Applications, vol. 29(2), pp. 397-403, Mar. 1993.

[9] ANSI/IEEE Std 1250-2002, IEEE Guide for Service to Equipment Sensitive to Momentary Voltage Disturbances.

[10] IEEE Std 493-2007, IEEE Recommended Practice for the Design of Reliable Industrial and Commercial Power Systems (Gold Book).

[11] A. Sannino, M. G. Miller, and M. H. J. Bollen, "Overview of Voltage Sag Mitigation", in Proc. IEEE Power Engineering Society Winter Meeting, Singapore, 23-27 Jan. 2000, pp. 2872-2878. 
[12] N. G. Hingorani, "Introducing Custom Power", IEEE Spectrum, pp. 41-48, June 1995.

[13] D. D. Sabin, and A. Sannino, "A Summary of the Draft IEEE P1409 Custom Power Application Guide", in Proc. IEEE Power Engineering Society Transmission and Distribution Conf. and Exposition, Dallas, USA, 7-12 Sep. 2003, pp. 1-6.

[14] C. Benachaiba and B. Ferdi, "Voltage quality improvement using dynamic voltage restorer", Electrical Power Quality and Utilization Journal, vol. 14(1), pp. 39-46,2008.

[15] N. H. Woodley, L. Morgan, and A. Sundaram, "Experience with an Inverter-Based Dynamic Voltage Restorer", IEEE Trans. on Power Delivery, vol. 14(3), pp. 1181-1186, July 1999.

[16] R. Affolter and B. Connell, "Experience with a Dynamic Voltage Restorer for a critical manufacturing facility", in Proc. IEEE Power Engineering Society Transmission and Distribution Conf. and Exposition, Dallas, USA, 7-12 Sep. 2003, pp. 937-939.

[17] S. Middlekauff and E. Collins, "System and Customer Impact: Considerations for Series Custom Power Devices", IEEE Trans. on Power Delivery, vol. 13(1), pp. 278-282, January 1998.

[18] J. E. Jipping, and W. E. Carter, "Application and Experience with a 15 kV Static Transfer Switch”, IEEE Trans. on Power Delivery, vol. 14(4), pp. 1477-1481, Oct. 1999.

[19] A. Sannino, "STS and Induction Motors", IEEE Industry Applications Magazine, pp. 50-57, July 2003.

[20] A. Sannino, J. Svensson, and T. Larsson, "Power Electronic Solutions to Power Quality Problems", Electric Power Systems Research, vol. 66, pp. 71-82, 2003.

[21] B. H. Chowdhury, "Power Quality", IEEE Potentials, pp. 5-11, Apr. 2001.

[22] M. McGranaghan and B. Roettger, "Economic Evaluation of Power Quality", IEEE Power Engineering Review, pp. 8-12, Feb. 2002.

[23] M. J. Sullivan, T. Vardell, and M. Johnson, "Power Interruption Costs to Industrial and Commercial Consumers of Electricity", IEEE Trans. on Industry Applications, vol. 33(5), pp. 1448-1458, Nov. 1997.

[24] J. V. Milanovic and C. P. Gupta, "Probabilistic Assessment of Financial Losses due to Interruptions and Voltage Sags", IEEE Trans. on Power Delivery, vol. 21(2), pp. 918-932, Apr 2006.

[25] D. V. Hertem, M. Didden, J. Driesen, and R. Belmans, "Choosing the Correct Mitigation Method Against Voltage Dips and Interruptions: A Customer-Based Approach", IEEE Trans. on Power Delivery, vol. 22(1), pp. 331-391, Jan. 2007.

[26] A. Maitra, A, M. Gaiiad, and T. A. Short, "Assessing Financial Feasibility of PQ Improvement Devices Using Monte Carlo Simulations", in Proc. $8^{\text {th }}$ Intemational Conference on Probabilistic Methods Applied to Power Systems, Iowa State University, Ames, Iowa, USA, September 2004, pp. 569-574.
[27] A. Baggini and F. Bua, "Investment Analysis for Power Quality Solutions", Leonardo Power Quality Initiative (LPQI): Power Quality Application Guide, Chapter 2.5, June 2004.

[28] T. Thasananutariya, S. Chatratana, and M. McGranaghan, "Economic evaluation of solution alternatives for voltage sags and momentary interruptions", Electrical Power Quality and Utilisation Magazine, vol. 1(2), pp. 17-26, Dec. 2005.

[29] M. Didden, R. Belmans, W. D'haeseeler, "Persuading Consumers to Invest in Voltage Sag Mitigation Devices", in Proc. EPRI Power Quality Assurance (PQA) Conf., Portland, USA, June 2002, pp. 1-12.

[30] J. Han and G. Jang, "Probabilistic life cycle cost analysis of custom power devices for voltage sags and interruptions mitigation", in Proc. IEEE Transmission \& Distribution Conference \& Exposition: Asia and Pacific, Seoul, Korea, Oct. 2009, pp. 1 - 4

\section{Prof. Dr. Mahmoud Ahmed El-Gammal}

Received the Ph. D. degree from Tohoku University, Japan. Recently, he is the head of Electrical Power, Machines, and Automatic Control, Department of Electrical Engineering, Faculty of Engineering, Alexandria University. He published three books, supervised over $25 \mathrm{Ph}$. D. and M. Sc. theses, and published over 25 papers. His recent research interests include power system analysis, voltage stability, VAR compensation, SCADA systems, power quality and custom power devices.

\section{A. Prof. Dr. Amr Yehia Abou-Ghazala}

Received the $\mathrm{Ph}$. D. degree from Old Dominion University, Norfolk VA, United States in 1998. Recently, he is an assisstant professor of Electrical Power Engineering at the Faculty of Engineering, Alexandria University. His recent research interests include dynamic stability of power systems, application of artificial intelligence in electrical power systems, substation automation, power quality and electrical safety.

\section{Eng. Tarek El-Shennawy}

Received the B. Sc. and M. Sc. degrees in electrical engineering from Alexandria University, Egypt, in 1995 and 2002, respectively. He is currently working towards his $\mathrm{Ph}$. D. degree. Recently he is the head of electrical engineering department at Alexandria National Refining and Petrochemicals Co. (ANRPC). His interests include power quality and the applications of modern power equipment in industrial distribution systems. 